Revista de Economia Política, vol. 40, $n^{\circ}$ 1, pp. 117-137, janeiro-março/2020

\title{
Poupança externa e crescimento econômico brasileiro: uma análise de duas visões díspares
}

\author{
Foreign savings and Brazilian economic growth: \\ an analysis of two disparate views
}

\author{
KELLY CARDOSO FARO* \\ CLEOMAR GOMES DA SILVA**,***
}

\begin{abstract}
RESUMO: O objetivo do estudo é verificar empiricamente uma dicotomia na literatura econômica. A visão clássica alega ser possível e viável o crescimento com poupança externa, enquanto uma linha de pensamento crítico advoga que o influxo de recursos externos afeta os investimentos internos no curto prazo, quando o faz, sendo irrelevantes no longo prazo. A fim de buscar corroborações empíricas para a discussão posta nos valemos de modelos ARDL, aplicados à cointegração, com dados trimestrais, para o período 1999:4 a 2017:4. Os resultados indicaram uma aproximação ao entendimento da visão crítica, dado que a poupança externa não se apresentou estatisticamente significativa no longo prazo na explicação do crescimento econômico brasileiro.
\end{abstract}

PALAVRAS-CHAVE: Poupança externa; crescimento econômico; ARDL; cointegração.

ABSTRACT: The aim of this article is to analyze empirically a dichotomy in the economic literature. The classical view claims that growth with foreign savings is feasible and viable, while a line of critical thinking advocates that foreign capital inflows affect domestic investments only in the short run, being irrelevant for long run growth. The bounds testing ARDL approach to cointegration is applied from 1999:4 to 2017:4. Estimation results show that foreign savings does not appear to explain the Brazilian economic growth in the long run, which is more in line with the understanding of the critical view.

KEYWORDS: Foreign savings; economic growth; ARDL; cointegration.

JEL Classification: E63; F21; F32; F43.

\footnotetext{
* Professora da Universidade Federal de Mato Grosso, Campus Rondonópolis (CE/UFMT-CUR), Rondonópolis/MS, Brasil. E-mail: kcfaro@yahoo.com.br. Orcid: https://orcid.org/0000-0003-4668-2142.

** Professor do Programa de Pós-Graduação em Economia, Universidade Federal de Uberlândia (IE-UFU). E-mail: cleomargomes@ufu.br. Orcid: https://orcid.org/0000-0002-1543-9097.

*** O autor é Pesquisador do CNPQ e agradece o apoio financeiro do CNPQ e FAPEMIG. Submetido: 6/Agosto/2018; Aprovado: 19/Março/2019.
} 


\section{INTRODUÇÃO}

A discussão fiscal e os elevados déficits em conta-corrente em um número considerável de países ao redor do mundo têm permeado debates e pesquisas acadêmicas, dado o impacto causado na conjuntura econômica destas nações e no bem-estar da população em questão. Este debate se torna mais intenso quando se soma a ele o entendimento de que a manutenção deste déficit seria uma estratégia deliberada dos tomadores de decisão, com o intuito de utilizar o influxo de recursos externos (poupança externa), como estratégia de elevação dos níveis de investimento doméstico, ao supostamente suprir os déficits na poupança interna e, por sua vez, estimular crescimento econômico.

O movimento ascendente de mobilidade internacional de capitais, acentuado nos anos 1990 com o Plano Brady, implicava uma equalização na alocação de recursos entre os países por meio da transferência dos capitais excedentes dos países ricos para os pobres, estimulando o crescimento econômico de longo prazo dos países do segundo grupo. O influxo de poupança externa pelos países carentes de capital se daria via déficits em conta-corrente, transformando-os diretamente em investimentos produtivos nas economias locais e, supostamente, gerando uma melhora na eficiência alocativa dos recursos monetários e financeiros mundiais

A partir deste entendimento, a política de crescimento baseada na dependência da poupança externa passou a ser fortemente utilizada e recomendada nos países com baixas taxas de acumulação de capital, dada a oportunidade de ampliação de suas capacidades produtivas, com possível trajetória ascendente de crescimento econômico. Esta linha de pensamento, que neste trabalho chamaremos de tese convencional ou visão clássica, desconsiderou alguns efeitos decorrentes da manutenção permanente de déficits em conta-corrente, como o forte aumento da dívida externa, a taxa de câmbio sobrevalorizada constantemente, a elevação exacerbada do consumo interno e os entraves decorrentes dos limites ao endividamento.

Inúmeras pesquisas, dispostas na literatura, avaliam os efeitos deletérios da estratégia política de crescimento com poupança externa; a esta linha de argumentação demos o nome de visão crítica, a qual argumenta que a tese convencional ignora a possibilidade de os recursos externos captados serem formados majoritariamente por capitais especulativos. Além disso, este tipo de influxo externo pode provocar pequena alteração positiva nos investimentos apenas no curto prazo, quando há uma alta taxa de substituição da poupança interna pela externa. Todavia, estes modestos efeitos seriam dissipados nos médio e longo prazos quando sobrevém uma crise no balanço de pagamentos.

Desse modo, este artigo tem o escopo de analisar empiricamente esta dicotomia para o caso brasileiro, ou seja, verificar qual das duas visões díspares explica melhor a influência da poupança externa no crescimento do Produto Interno Bruto (PIB) do Brasil. Para isso, serão utilizados Modelos Autorregressivos de Defasagens Distribuídas (ARDL) aliados à análise de cointegração, para dados trimestrais de 1999:4 a 2017:4.

Este trabalho está dividido em quatro seções, além desta breve introdução, 
sendo que a seguinte abarca a revisão de literatura acerca dos impactos da política de crescimento nacional baseada na poupança externa a partir das duas linhas de argumentação definidas. Ademais, nesta seção também será feito um levantamento da literatura empírica nacional e internacional correlata. A terceira seção tratará dos pormenores da metodologia empírica utilizada e a base de dados coletada, enquanto a última seção corresponde aos resultados do estudo econométrico. Por fim, são apresentados os comentários conclusivos.

\section{REVISÃO DE LITERATURA}

O debate recente permeia a discussão relacionada ao uso do déficit em conta-corrente como política de crescimento, ou seja, a elevação da capacidade produtiva nacional com vista a elevar o produto interno brasileiro é dependente do influxo de recursos externos para suprir as debilidades na poupança interna. Esta estratégia deliberada de política econômica não é consensual na literatura econômica. Assim, a presente seção se centra em apresentar suscintamente os argumentos principais da discussão em voga na literatura econômica tendo como expoente da visão convencional/clássica os estudos de Feldstein e Horioka (1980); Dornbusch, Goldfajn e Valdés (1995); Obstfeld e Rogoff (2000); e Einchengreen e Leblang (2003), enquanto as apreciações de Bresser-Pereira e Nakano (2003); Damasceno (2007); Bresser-Pereira; Gonzalez e Lucinda (2008); Alves et al. (2010); Bresser-Pereira (2010) e Rocha e Oreiro (2011) se destacam com argumentos empíricos e analíticos de oposição a esta política.

\section{Poupança externa como saída aos países pobres em capital: visão clássica}

O pressuposto básico desta estratégia de crescimento é de que com elevadas taxas de poupança e investimento, a um determinado nível de progresso técnico, se impulsiona o crescimento econômico. Dessa forma, a poupança externa, atuando como financiamento ao investimento, promove crescimento econômico ao substituir os recursos internos insuficientes em países altamente endividados. A abertura da conta capital e uso da poupança externa como política de crescimento pressupõe que os países ricos, com elevadas taxas de acumulação de capital, transfiram seus recursos aos países mais pobres, transformando-os em capital produtivo.

Esta tese convencional baseia-se na ampliação das opções de investimento produtivo dos agentes à medida que a entrada de recursos externos supriria a poupança interna insuficiente. Um baixo estoque de capital de determinado país, em decorrência de baixa renda per capita, pode ser elevado por intermédio de empréstimos de recursos externos, que gerarão ampliação da capacidade produtiva e maior retorno do investimento. A contrapartida seriam os juros pagos futuramente ao se obterem os resultados produtivos, que não implicariam ônus pernicioso, mas apenas como condição necessária para se promover o crescimento.

O Quadro 1 faz um breve levantamento da literatura empírica que permeia 
esta visão da poupança externa impactando sobre o produto da economia. Há diferentes pesquisas empíricas, em temporalidade de análise e modelo utilizado, mas que se assemelham em salientar a defesa a transferência de recursos entre países com elevado estoque de capital perante países em desenvolvimento carente destes recursos por intermédio de déficits em conta-corrente. Feldstein e Horioka (1980) são precursores desta visão. Para os autores, ao atuar como meio de financiamento e investimento, a poupança externa promove crescimento econômico ao substituir os recursos internos insuficientes em países altamente endividados e com ínfimos estoques de capital.

O pressuposto básico desta estratégia é que com elevadas taxas de poupança e investimento, a um determinado nível de progresso técnico, se impulsiona o crescimento econômico. Todavia, os países com elevado estoque de capital teriam ganhos de bem-estar à medida que aplicam suas poupanças a uma taxa de remuneração maior do que a doméstica. Portanto, na teoria clássica os rendimentos marginais dos capitais seriam otimizados, tendendo a se igualarem, e tornando possível o bem-estar de países de diferentes estágios de desenvolvimento em nível ótimo.

Dornbusch, Goldfajn e Valdés (1995) reforçam que a taxa de câmbio real é um preço relativo chave, dado que na maioria das vezes ela está atrelada à variável de política. Isso representa um mercado de capitais excessivamente flexível e requer o manejo da taxa de câmbio adequado à finalidade de amplificar os efeitos da política de substituição da poupança externa sobre a interna.

Reinhart e Talvi (1999), ao compararem analiticamente casos específicos de países em desenvolvimento na Ásia e na África, alegam que os esporádicos momentos históricos de crescimento daquelas economias foram possíveis e induzidos pela captação de poupança externa, em condução teórica linear com a argumentação clássica.

Obstfeld e Rogoff (2000) discorrem sobre os canais da integração financeira internacional e advogam que as economias domésticas, com os influxos de poupança externa, podem complementar a poupança interna, içar o investimento e promover o crescimento a partir dos fluxos de capitais. O argumento é que em países em desenvolvimento, além da escassez de capital, os baixos níveis de renda e de poupança constituiriam restrições ao crescimento. Logo, a poupança externa, na forma de entrada líquida de capitais, permite o aumento da renda que, por sua vez, possibilitaria a elevação da poupança e investimento doméstico, instituindo um círculo virtuoso no qual haveria uma expansão econômica sustentada.

Einchengreen e Leblang (2003), ao analisarem 21 países, sugerem que o efeito líquido da conexão entre os fluxos internacionais e crescimento são específicos do contexto conjuntural da economia receptora dos recursos. Os autores atestam que tais efeitos seriam positivos em períodos de instabilidade financeira, quando a capacidade de estimular investimentos é nula, dada as fortes incertezas, mas negativos em tempos de calmaria nas economias em desenvolvimento. Neste caso, o incentivo à poupança interna seria a decisão política mais adequada. Dessa forma, eles sugerem que a liberalização da conta de capital tem benefícios suscetíveis de dominar os seus custos quando o sistema financeiro da economia receptora é robusto. 
Quadro 1:

Literatura Empírica: Efeitos da Poupança Externa sobre o PIB: Visão Clássica

\begin{tabular}{|c|c|c|c|c|}
\hline Autoria & Países & Método & Período & Resultado(s) \\
\hline $\begin{array}{l}\text { Feldstein e } \\
\text { Horioka (1980) }\end{array}$ & $\begin{array}{l}16 \text { países } \\
\text { da OCDE }\end{array}$ & $\begin{array}{l}\text { Mínimos Quadra- } \\
\text { dos Generalizados }\end{array}$ & 1960-1974 & $\begin{array}{c}\text { Forte correlação entre poupança } \\
\text { externa e investimento }\end{array}$ \\
\hline $\begin{array}{l}\text { Schmidt-Hebel } \\
\text { et al. (1992) }\end{array}$ & $\begin{array}{l}10 \text { países } \\
\text { desenvolvi- } \\
\quad \text { dos }\end{array}$ & Dados em Painel & 1970-1985 & $\begin{array}{l}\text { Substituição da poupança } \\
\text { interna pela externa é } \\
\text { significativa }\end{array}$ \\
\hline $\begin{array}{l}\text { Dornbusch } \\
\text { et al. (1995) }\end{array}$ & $\begin{array}{l}\text { Argentina, } \\
\text { Brasil, Chile } \\
\text { e México }\end{array}$ & $\begin{array}{l}\text { Comparação entre } \\
\text { indicadores } \\
\text { macroeconômicos }\end{array}$ & 1978-1995 & $\begin{array}{l}\text { Captação externa de recursos } \\
\text { é fonte de financiamento } \\
\text { do crescimento de países } \\
\text { em desenvolvimento se } \\
\text { houver manipulação estratégica } \\
\text { da taxa câmbio }\end{array}$ \\
\hline $\begin{array}{l}\text { Uthoff e } \\
\text { Titelman } \\
\text { (1998) }\end{array}$ & $\begin{array}{l}15 \text { países: } \\
\text { Am. Latina } \\
\text { e Caribe }\end{array}$ & $\begin{array}{l}\text { Dados } \\
\text { em Painel }\end{array}$ & 1972-1993 & $\begin{array}{c}\text { Elevadas taxas de substituição } \\
\text { da poupança externa pela } \\
\text { poupança interna }\end{array}$ \\
\hline $\begin{array}{c}\text { Obstfeld e } \\
\text { Rogoff (2000) }\end{array}$ & $\begin{array}{l}\text { Mesmos de } \\
\text { Feldstein } \\
\text { e Horioka } \\
\text { (1980) }\end{array}$ & VAR & 1990-1997 & $\begin{array}{c}\text { Fluxos de capitais internacionais } \\
\text { favorecem países pobres em } \\
\text { poupança doméstica }\end{array}$ \\
\hline $\begin{array}{l}\text { Einchengreen } \\
\text { e Leblang } \\
\text { (2003) }\end{array}$ & $\begin{array}{l}21 \text { países - } \\
\text { FMI }\end{array}$ & $\begin{array}{l}\text { Séries } \\
\text { Temporais }\end{array}$ & 1980-1997 & $\begin{array}{l}\text { Uma nação dependente de } \\
\text { recursos externos só aufere } \\
\text { benefícios superiores } \\
\text { ao custos quando seu } \\
\text { sistema financeiro é robusto }\end{array}$ \\
\hline
\end{tabular}

\section{Poupança externa não promove crescimento: visão crítica}

Para a manutenção da política de crescimento com poupança externa a taxa de câmbio real deve ser mantida apreciada. Isso revela aos pensadores da linha crítica a inviabilidade desta política, na medida em que estes percebem que o influxo de poupança externa não resulta em elevação do investimento produtivo, mas sim em aumento do consumo e do endividamento externo. Desse modo, a proposição de contestação é que "[...] uma alta taxa de substituição da poupança interna pela externa causa endividamento externo e implica a obrigação de remunerá-lo sem que haja um aumento correspondente e garantido da capacidade produtiva do país" (Bresser-Pereira; 2007a, p. 5).

O Quadro 2 elenca a literatura empírica crítica à adoção deliberada de política de crescimento pautada na dependência da poupança externa. A priori, é possível notar a discordância dos resultados, ainda considerando as diferenças metodológicas e temporais, de algumas pesquisas aqui presentes, ante as do Quadro 1, no que tange a elencar os efeitos positivos e negativos (ou irrisórios) da poupança externa sobre o crescimento. 
Rocha e Oreiro (2011) desenvolvem uma modelo pós-keynesiano de crescimento para uma economia aberta cuja implicação central é que a influência da poupança externa, ao acumular endividamento além de certo limite, tem impacto negativo sobre o nível de atividade econômica. O resultado do modelo dinâmico não linear desenvolvido pelos autores evidencia um mecanismo de transmissão potencial de restrições de longo prazo gerado pelo influxo de poupança externa sobre o crescimento. Dessa forma, nos médio e longo prazos o endividamento externo excessivo configuraria uma situação de estagnação econômica e não de crescimento, por atingir o equilíbrio em uma situação de baixa lucratividade e inexpressivo retorno do capital.

Em consenso argumentativo, Bresser-Pereira, Gonzalez e Lucinda (2008) expõem que recorrentes déficits em conta-corrente, usados deliberadamente como meio de obtenção de poupança externa, juntamente com a abertura da conta capital, causam fragilidade financeira e crise de balanço de pagamentos, além de endividamento externo. Isso seria consequência da decisão dos credores externos de suspenderem a rolagem dos créditos dos países altamente endividados.

Aurélio (2007) argumenta que o uso da poupança externa resultaria em estímulos ao investimento apenas nos casos de países que estejam passando por momentos de crescimento econômico rápido e exacerbado. A razão para isso é que recursos externos alavancariam as oportunidades de investimentos já propícias pelo momento econômico positivo no qual estas economias se encontrariam. Portanto, esta política só seria bem-sucedida em um caso especial e com redução da propensão a consumir dos agentes, situação não pertinente aos países latino-americanos.

Em Bresser-Pereira e Nakano (2003) a centralidade da argumentação crítica à política de crescimento com poupança externa, chamada de "política de conta-corrente fraca", baseia-se nos limites macroeconômicos ao endividamento externo. O estudo sugere a existência de um limite de déficit em conta-corrente que determinado país pode suportar, dado que a um certo nível da relação dívida/PIB a solvência sofre restrições ligadas a impedimentos dos credores externos a novas dívidas pois, mesmo com juros crescentes, são elevados os riscos de novos endividamentos para pagar as anteriores. Ademais, os agentes internos também começam a exigir juros mais altos e os investimentos produtivos se reduzem, afetando negativamente a estabilidade e o crescimento econômico. Por fim, os autores explicam que o entendimento dos formuladores da política de crescimento com poupança externa é que os efeitos negativos de longo prazo seriam arrefecidos dado que os déficits em conta-corrente se equilibrariam, o que não condiz com a realidade.

Bresser-Pereira (2007a) alega que o impacto de apreciação na taxa de câmbio gera aumento subsequente nos salários reais e nas importações e, dada a alta propensão a consumir, os agentes tenderão a consumir quase a totalidade de seus ganhos. Já os capitalistas, mesmo com uma redução de seus lucros (pelo pagamento de maiores salários), não reduzirão seu consumo, gerando diminuição dos investimentos. Isto significa que o influxo de recursos externos será fortemente compen- 
Quadro 2: Literatura Empírica: Efeitos da Poupança Externa sobre o PIB: Visão Crítica

\begin{tabular}{|c|c|c|c|c|}
\hline Autoria & Países & Método & Período & Resultado(s) \\
\hline $\begin{array}{c}\text { Edwards } \\
\text { (1995) }\end{array}$ & 25 países & $\begin{array}{l}\text { Dados em } \\
\text { Painel }\end{array}$ & 1970-1992 & $\begin{array}{c}\text { Inexpressivo grau de } \\
\text { transmissão da poupança } \\
\text { externa para o PIB }\end{array}$ \\
\hline $\begin{array}{l}\text { Aurélio } \\
\text { (1997) }\end{array}$ & Brasil & VAR & 1976-1996 & $\begin{array}{c}\text { Captação de recursos } \\
\text { externos não estimula } \\
\text { investimentos domésticos } \\
\text { no longo prazo }\end{array}$ \\
\hline $\begin{array}{l}\text { Bresser- } \\
\text {-Pereira e } \\
\text { Nakano } \\
(2003)\end{array}$ & 51 países & $\begin{array}{c}\text { Taxa de } \\
\text { substituição } \\
\text { da poupança } \\
\text { externa } \\
\text { com o PIB }\end{array}$ & 1979-1998 & $\begin{array}{c}\text { Elevação em } 1 \% \text { do déficit } \\
\text { em conta-corrente eleva o } \\
\text { PIB em apenas } 0,005 \% \text { no } \\
\text { curto prazo }\end{array}$ \\
\hline $\begin{array}{l}\text { Bresser- } \\
\text {-Pereira } \\
(2006)\end{array}$ & Brasil & $\begin{array}{c}\text { Taxa de } \\
\text { substituição } \\
\text { da poupança } \\
\text { interna com } \\
\text { externa }\end{array}$ & $\begin{array}{l}1994-1999 \\
2000-2005\end{array}$ & $\begin{array}{l}\text { Se recursos externos } \\
\text { captados forem } \\
\text { especulativos a taxa de } \\
\text { substituição é nula }\end{array}$ \\
\hline $\begin{array}{l}\text { Bresser- } \\
\text {-Pereira; } \\
\text { Gonzalez } \\
\text { e Lucinda } \\
\text { (2008) }\end{array}$ & $\begin{array}{l}12 \text { países } \\
\text { emergentes: } \\
\text { Ásia e Am. } \\
\text { Latina }\end{array}$ & $\begin{array}{l}\text { GMM; VAR e } \\
\text { LOGIT-PROBIT }\end{array}$ & 1990-2002 & $\begin{array}{l}\text { Política econômica de } \\
\text { crescimento com poupança } \\
\text { externa é ineficiente e causa } \\
\text { sobreapreciação cambial }\end{array}$ \\
\hline $\begin{array}{c}\text { Alves et al. } \\
\text { (2010) }\end{array}$ & Brasil & $\begin{array}{l}\text { Funções de } \\
\text { Resposta a } \\
\text { Impulso e } \\
\text { Causalidade } \\
\text { Granger }\end{array}$ & $1994-2010$ & $\begin{array}{c}\text { Déficits em conta-corrente } \\
\text { para financiar o crescimento } \\
\text { com poupança externa } \\
\text { provocam crise na balança } \\
\text { de pagamentos }\end{array}$ \\
\hline $\begin{array}{l}\text { Rocha } \\
\text { e Oreiro } \\
(2011)\end{array}$ & 73 países & $\begin{array}{c}\text { Painel } \\
\text { Dinâmico }\end{array}$ & 1980-2000 & $\begin{array}{c}\text { Efeitos negativos da } \\
\text { poupança externa sobre } \\
\text { o crescimento econômico } \\
\text { de longo prazo }\end{array}$ \\
\hline
\end{tabular}

sado pelo arrefecimento da poupança interna decorrente do aumento do consumo e, portanto, não estimularia o crescimento econômico além do curto prazo.

Dessa forma, as premissas críticas baseiam-se na inexpressiva elevação do investimento interno no longo prazo, dado os efeitos apreciativos sobre a taxa de câmbio e a propensão a consumir dos agentes. Além disso, levaria à possibilidade de crise fiscal, em decorrência dos limites ao endividamento, e acarretaria distanciamento da estabilidade macroeconômica, com possibilidade de crise de demanda interna e da dívida externa. 


\section{ANÁLISE EMPÍRICA DOS IMPACTOS DA \\ POUPANÇA EXTERNA SOBRE O PIB BRASILEIRO}

\section{Metodologia}

A metodologia empírica econométrica aplicada nesta pesquisa é o Modelo Autorregressivo de Defasagem Distribuída (ARDL) aliado à cointegração, conforme referência dos trabalhos de Pesaran e Shin (1999) e Pesaran et al. (2001). O procedimento destes autores é uma continuação pormenorizada dos modelos ADL clássicos, aplicados em séries temporais estacionárias, para o estudo de relações em nível com variáveis integradas de ordem $1, \mathrm{I}(1)$.

Pesaran et al. (2001) propõem um método de cointegração que pode abarcar um conjunto de variáveis cujas ordens de integração diferem entre si, o que auxilia muito na utilização de dados puramente $\mathrm{I}(0)$, puramente $\mathrm{I}(1)$, ou com as duas ordens de integração ${ }^{1}$. Ademais, Pesaran e Shin (1999) explicam que esse mesmo teste de cointegração nos modelos ARDL apreende as relações de longo prazo em amostras pequenas de dados de modo mais eficiente e permite que um nível ótimo de defasagens possa ser determinado para cada uma das variáveis do modelo ARDL. Estes diferenciais do método justificam a escolha desta metodologia para a averiguação da relação entre a poupança externa e o crescimento econômico brasileiro.

O modelo ARDL é estimado inicialmente para se analisar se há cointegração das variáveis no longo prazo. A partir disso, estimam-se os coeficientes de longo e curto prazo, assim como a velocidade de ajuste ao equilíbrio de longo prazo. Desse modo, o modelo estimado na forma de correção de erros (ARDL-ECM) origina-se da equação genérica do modelo ARDL e pode ser especificado a partir da primeira diferença, conforme explicitado abaixo.

$$
\Delta y_{t}=a_{0}+a_{1} \tau+\delta_{1} y_{t-1}+\delta_{2} x_{t-1}+\sum_{i=1}^{n} \theta_{1 i} \Delta y_{t-i}+\sum_{i=1}^{n} \theta_{2 i} \Delta x_{t-i}+\varepsilon_{t}
$$

As variáveis indicam: $\Delta$ a diferença, $a_{0}$ e $a_{1}$ são termos de constante e tendência; $\delta_{i}, \mathrm{i}=1,2$ são parâmetros de longo prazo; $\theta_{i} \mathrm{i}=1$,2 são parâmetros de curto prazo; e $\varepsilon_{t}$ é o termo de erro, ou distúrbios do tipo ruído branco.

A apreciação da cointegração de Pesaran et al. (2001) se faz com um teste para a observação da significância conjunta dos parâmetros de longo prazo, o que indica que a validação dos coeficientes de longo prazo ocorre quando a cointegração é estabelecida. Pesaran et al. (2001) fornecem uma banda de valores críticos em que a banda superior equivale à hipótese de que todas as variáveis são I(1) e o nível inferior determina que as variáveis do modelo ARDL são estacionárias. A utilização (ou não) de intercepto e tendência são hipóteses também consideradas.

A estatística-F do teste é comparada com a banda de valores críticos que fora

\footnotetext{
${ }^{1}$ Desde que I(0) e I(1), uma vez que o modelo não é especificado para I(2).
} 
determinada. A hipótese nula $\left(H_{0}\right)$ é de não existência de vetores de cointegração $H_{o}=\delta_{1}=\delta_{2}=0$ e a hipótese alternativa $\left(H_{\mathrm{A}}\right)$ é de existência de relação de longo prazo entre as variáveis do modelo $H_{A}=\delta_{1} \neq \delta_{2} \neq 0$. Com isso, entende-se que a hipótese nula não é rejeitada se a estatística-F ficar abaixo da banda inferior de valores críticos e, acima da banda superior, a hipótese nula é rejeitada. Será preciso conhecer a ordem de integração das variáveis no caso da estatística $\mathrm{F}$ ficar dentro do intervalo dos valores críticos. A partir desta metodologia apresentada estimaremos as equações do modelo.

\section{Dados}

As variáveis utilizadas na estimação dos modelos ARDL para a captação dos efeitos dos fluxos de recursos externos sobre o crescimento da economia brasileira possuem periodicidade trimestral (1999:4 a 2017:4) e estão definidas como se segue:

- $e_{t}=$ Log do Índice da Taxa de Câmbio Real (valor de final de trimestre, dessazonalizado) - Fonte: BIS;

- $r_{t}=$ Taxa de Juros Over Selic (\% diária) (valor final de período) - Fonte: Banco Central do Brasil;

- $\pi_{t}=$ Log do índice IPCA (Índice Nacional de Preços ao Consumidor Amplo) (valor de final de trimestre, dessazonalizado) - Fonte: IBGE;

- $y_{t}=$ Log do índice do Produto Interno Bruto (PIB) com ajuste sazonal - Fonte: IBGE;

- $I_{t}=$ Log do índice da Formação Bruta de Capital Fixo (proxy do Investimento) com ajuste sazonal (fim de período) - Fonte: IBGE;

- $s i_{t}=$ Índice da Poupança Interna (NFSP + PP) (R \$ milhões) (deflacionado pelo IPCA e dessazonalizado) - Fonte: IBGE;

- $s i D_{t}=$ Série exatamente idêntica à $s i_{t}$, todavia foram diluídos $\mathrm{R} \$ 115$ bi relativos às pedaladas fiscais do Governo Dilma Rousseff no período de 2013:3 a 2015:4;

- $s e_{t}=$ Poupança Externa (Transações Correntes $-\mathrm{R} \$$ milhões) (transformado para base 100, deflacionado pelo IPCA e dessazonalizado) - Fonte: IBGE;

- $i d p_{t}=$ Investimento Direto no País (saldo - R \$ milhões) (transformado para base 100, deflacionado pelo IPCA e dessazonalizado) - Fonte: Banco Central do Brasil.

As variáveis macroeconômicas em número-índice foram modificadas para logaritmo natural a fim de que os resultados possam ser lidos em variações percentuais. Cabe destacar que, de acordo com a própria fonte de dados BIS, um aumento no índice da taxa de câmbio real indica apreciação. Como no Brasil o entendimento é de que uma elevação do índice se refere a uma depreciação foi feita uma inversão simples da taxa (1/BIS).

Ademais, a série para o índice de Poupança Interna foi obtida com a soma da $($ NFSP + PP) Necessidade de Financiamento do Setor Público (NFSP = necessidade 
de financiamento do setor público expressa em resultado primário do setor público - s/ desvalorização cambial - acum. 12 meses - $\mathrm{R}$ \$ (milhões) - Bacen) com a poupança privada (PP: formada pela equação: (S-I)/PIB. Sendo 'S' a poupança nacional bruta, trimestral (R\$ mi- ref. 2010) e o Investimento 'I', representada por sua proxy: formação bruta de capital fixo, trimestral (R \$ mi- ref. 2010), ambas disponibilizadas pelo Banco Central do Brasil. As séries foram subtraídas e seu resultado foi posteriormente dividido pelo PIB, série histórica, trimestral, valores correntes (R $\$ \mathrm{mi})$, disponível no IBGE. Já a série (= poupança externa) refere-se ao saldo das transações correntes US\$ (milhões), convertida em R \$ via taxa de câmbio - R \$ / US\$ - comercial - venda - média - Fonte: Banco Central do Brasil.

\section{Modelo}

Para a análise da relação da política de crescimento com poupança externa estimaremos seis modelos ARDL, os quais testaram as relações entre o influxo de recursos externos sobre o crescimento econômico brasileiro. Os modelos buscam verificar a influência da poupança externa (se) e interna (si) sobre o produto, utilizando importantes variáveis macroeconômicas como controle, tais como a taxa de câmbio, o nível de investimento, a taxa de juros Selic e a taxa de inflação do IPCA.

A escolha das variáveis e a especificação das equações de cada modelo estão em linhas com trabalhos empíricos correlatos, a saber: Feldstein e Horioka (1980); Bresser-Pereira e Nakano (2003); Alves et al. (2010); Rocha e Oreiro (2011). Os modelos estão descritos a seguir:

\section{Modelo 1:}

$$
\begin{aligned}
& \Delta y_{t}=a_{0}+a_{1} \tau+\beta_{1} y_{t-1}+\beta_{2} s e_{t-1}+\beta_{3} e_{t-1}+\beta_{4} \pi_{t-1}+\beta_{5} r_{t-1}+\sum_{i=0}^{n} \beta_{6} \Delta y_{t-i}+ \\
& \sum_{i=0}^{n} \beta_{7} \Delta s e_{t-i}+\sum_{i=0}^{n} \beta_{8} \Delta e_{t-i}+\sum_{i=0}^{n} \beta_{9} \Delta \pi_{t-i}+\sum_{i=0}^{n} \beta_{10} \Delta r_{t-i}+u_{t}
\end{aligned}
$$

\section{Modelo 2}

$$
\begin{aligned}
& \Delta y_{t}=a_{0}+a_{1} \tau+\beta_{1} y_{t-1}+\beta_{2} s e_{t-1}+\beta_{3} e_{t-1}+\beta_{4} \pi_{t-1}+\beta_{5} r_{t-1}+\beta_{6} l_{t-1}+\beta_{7} s i_{t-1}+ \\
& \sum_{i=0}^{n} \beta_{8} \Delta y_{t-i}+\sum_{i=0}^{n} \beta_{9} \Delta s e_{t-i}+\sum_{i=0}^{n} \beta_{10} \Delta e_{t-i}+\sum_{i=0}^{n} \beta_{11} \Delta \pi_{t-i}+\sum_{i=0}^{n} \beta_{12} \Delta r_{t-i}+ \\
& \sum_{i=0}^{n} \beta_{13} \Delta l_{t-i}+\sum_{i=0}^{n} \beta_{14} \Delta s i_{t-i}+u_{t}
\end{aligned}
$$

\section{Modelo 3}

$$
\begin{aligned}
& \Delta y_{t}=a_{0}+a_{1} \tau+\beta_{1} y_{t-1}+\beta_{2} s e_{t-1}+\beta_{3} e_{t-1}+\beta_{4} \pi_{t-1}+\beta_{5} r_{t-1}+\beta_{6} l_{t-1}+\beta_{7} s i D_{t-1}+ \\
& \sum_{i=0}^{n} \beta_{8} \Delta y_{t-i}+u_{t} \sum_{i=0}^{n} \beta_{9} \Delta s e_{t-i}+\sum_{i=0}^{n} \beta_{10} \Delta e_{t-i}+\sum_{i=0}^{n} \beta_{11} \Delta \pi_{t-i}+\sum_{i=0}^{n} \beta_{12} \Delta r_{t-i}+ \\
& \sum_{i=0}^{n} \beta_{13} \Delta l_{t-i}+\sum_{i=0}^{n} \beta_{14} \Delta s i D_{t-i}+u_{t}
\end{aligned}
$$

\section{Modelo 4}

$$
\begin{aligned}
& \Delta y_{t}=a_{0}+a_{1} \tau+\beta_{1} y_{t-1}+\beta_{2} i d p_{t-1}+\beta_{3} e_{t-1}+\beta_{4} \pi_{t-1}+\beta_{5} r_{t-1}+\sum_{i=0}^{n} \beta_{6} \Delta y_{t-i}+ \\
& \sum_{i=0}^{n} \beta_{7} \Delta i d p_{t-i}+\sum_{i=0}^{n} \beta_{8} \Delta e_{t-i}+\sum_{i=0}^{n} \beta_{9} \Delta \pi_{t-i}+\sum_{i=0}^{n} \beta_{10} \Delta r_{t-i}+u_{t}
\end{aligned}
$$




\section{Modelo 5}

$$
\begin{aligned}
& \Delta y_{t}=a_{0}+a_{1} \tau+\beta_{1} y_{t-1}+\beta_{2} i d p_{t-1}+\beta_{3} e_{t-1}+\beta_{4} \pi_{t-1}+\beta_{5} r_{t-1}+\beta_{6} l_{t-1}+\beta_{7} s i_{t-1}+ \\
& \sum_{i=0}^{n} \beta_{8} \Delta y_{t-i}+\sum_{i=0}^{n} \beta_{9} \Delta s e_{t-i}+\sum_{i=0}^{n} \beta_{10} \Delta e_{t-i}+\sum_{i=0}^{n} \beta_{11} \Delta \pi_{t-i}+\sum_{i=0}^{n} \beta_{12} \Delta r_{t-i}+ \\
& \sum_{i=0}^{n} \beta_{13} \Delta l_{t-i}+\sum_{i=0}^{n} \beta_{14} \Delta s i_{t-i}+u_{t}
\end{aligned}
$$

\section{Modelo 6}

$$
\begin{aligned}
& \Delta y_{t}=a_{0}+a_{1} \tau+\beta_{1} y_{t-1}+\beta_{2} i d p_{t-1}+\beta_{3} e_{t-1}+\beta_{4} \pi_{t-1}+\beta_{5} r_{t-1}+\beta_{6} l_{t-1}+ \\
& \beta_{7} s i D_{t-1}+\sum_{i=0}^{n} \beta_{8} \Delta y_{t-i}+\sum_{i=0}^{n} \beta_{9} \Delta i d p_{t-i}+\sum_{i=0}^{n} \beta_{10} \Delta e_{t-i}+\sum_{i=0}^{n} \beta_{11} \Delta \pi_{t-i}+ \\
& \sum_{i=0}^{n} \beta_{12} \Delta r_{t-i}+\sum_{i=0}^{n} \beta_{13} \Delta l_{t-i}+\sum_{i=0}^{n} \beta_{14} \Delta s i D_{t-i}+u_{t}
\end{aligned}
$$

onde, $a_{0}$ e $a_{1}$ são termos constante e tendência, $\beta_{i}, i=1,2,3, \ldots, n$ são parâmetros do modelo; e $u_{t}$ se refere ao termo de erro.

As variáveis utilizadas possuem periodicidade trimestral (1999:4 a 2017:4) e estão definidas conforme se segue: = Poupança Interna; = Poupança Externa; = Investimento Direto no país; = Log do Índice do PIB; = Taxa de juros Selic; = Log da Taxa de Câmbio Real; = Log do Índice Formação Bruta de Capital Fixo (proxy do investimento); = log do Índice de Preços ao Consumidor Amplo (IPCA), elencados acima.

\section{RESULTADOS DA ANÁLISE EMPÍRICA}

\section{Testes de Raiz Unitária}

Conforme já enfatizado, se as estatísticas do teste de cointegração ficarem entre os valores críticos calculados por Pesaran et al. (2001), é necessário conhecer a ordem de integração das variáveis para a rejeição da hipótese nula. Desse modo, foram realizados quatro testes de raiz unitária: Augmented Dickey Fuller (ADF), Phillips-Perron (PP), Kwiartkwoski-Phillips-Schmidt-Shin (KPSS) e o Teste de Dickey-Fuller modificado pela estimação por Mínimos Quadrados Generalizados (DF-GLS)². Os resultados são apresentados na Tabela 1 e mostram que sete das variáveis componentes desta pesquisa são integradas de ordem 1 (não estacionárias), enquanto duas séries, taxa de câmbio $\left(e_{t}\right)$ e poupança externa $\left(s e_{t}\right)$, se classificaram como integradas de ordem zero (estacionárias).

\footnotetext{
${ }^{2}$ Para maiores detalhes de cada teste de raiz unitária ver Elliot et al. (1996), Kwiatkowski et al. (1992), Dickey e Fuller (1979) e Phillips e Perron (1988).
} 
Tabela 1: Testes de Raiz Unitária (1999:4 a 2017:4)

\begin{tabular}{c|c|c|c|c|c}
\hline Variáveis & ADF & DF-GLS & PP & KPSS & Classificação \\
\hline$y_{t}$ & $-1,50$ & $-0,83$ & $-1,37$ & $1,15^{*}$ & I(1) \\
\hline$e_{t}$ & $-1,89$ & $-1,52$ & $-1,96$ & $0,24^{*}$ & I(0) \\
\hline$r_{t}$ & $-2,28$ & $-0,67^{* *}$ & $-1,66$ & $0,80^{*}$ & $\mid(1)$ \\
\hline$\pi_{t}$ & $-0,45$ & $-0,81^{* *}$ & $-0,73$ & $1,19^{*}$ & $\mid(1)$ \\
\hline$I_{t}$ & $-1,33$ & $-0,36$ & $-1,27$ & 0,94 & $\mid(1)$ \\
\hline$s e_{t}$ & $-2,22$ & $-2,21$ & $-2,85$ & $0,23^{*}$ & $\mid(0)$ \\
\hline$i d p_{t}$ & $-2,61$ & $-1,58$ & $-3,56$ & $0,92^{*}$ & $\mid(1)$ \\
\hline$s i_{t}$ & $-0,05$ & $-0,04$ & $-0,33$ & $0,58^{* *}$ & $\mid(1)$ \\
\hline$s i D_{t}$ & $-0,07$ & $-0,05$ & $-0,34$ & $0,59^{*}$ & $\mid(1)$ \\
\hline
\end{tabular}

ADF, DF-GLS e PP: = série com raiz unitária (não estacionária: I(1))

KPSS: = série com raiz unitária

${ }^{*} e^{* *}$ denota rejeição da hipótese nula a $1 \%$ e $5 \%$ de nível de significância, respectivamente.

\section{Estimações dos modelos ARDL}

A realização dos testes de raiz unitária permite observar que as variáveis selecionadas se apresentam na forma de um mix de ordem de integração. Tal fato revela consonância com os preceitos para a realização dos modelos ARDL, que compreendem um conjunto de variáveis cujas ordens de integração diferem entre si. Dessa forma, o passo seguinte é a definição das defasagens de cada modelo. Utilizando o Critério de Akaike, com quatro defasagens, o modelo 1 é definido como ARDL $(3,0,4,3,1)$, o modelo 2 como ARDL $(1,0,2,0,1,2,1)$, o modelo 3 ARDL $(1,0,2,0,1,2,1)$, o modelo 4 ARDL $(3,1,4,0,1)$, o modelo 5 ARDL $(1,0,4,0,1,2,1)$ e, por fim, o modelo 6 ARDL $(1,0,2,0,1,2,1)$, tal como descrito na Tabela 2.

Destaca-se que as defasagens do modelo 3 são idênticas às do modelo 2 , e o mesmo efeito ocorre do modelo 6 em relação ao 5. Isso acontece devido à similaridade das variáveis utilizadas na estimação destes pares de modelos. Apenas a variável "si $D_{t}$ " diferencia o modelo 3 do 2 , e o modelo 6 do 5 . Esta é a variável referente à série poupança interna brasileira com os valores monetários das "pedaladas fiscais" que ocorreram no governo Dilma Rousseff diluídos nos anos de seu governo.

A Tabela 2 também apresenta os resultados do teste LM de diagnóstico de correlação serial nos resíduos. Como a hipótese nula é de ausência de correlação serial, os resultados estimados apontam ausência de autocorrelação nos seis modelos estimados. 
Tabela 2: Modelos ARDL - Defasagens e Teste de Correlação Serial

\begin{tabular}{|c|c|c|}
\hline Modelo & $\begin{array}{c}\text { ARDL } \\
\text { Defasagens }\end{array}$ & $\begin{array}{l}\text { Teste LM de Autocorrelação } \\
\text { [Prob] }\end{array}$ \\
\hline Modelo 1 & $(3,0,4,3,1)$ & $\begin{array}{c}0,23 \\
{[0,98]}\end{array}$ \\
\hline Modelo 2 & $(1,0,2,0,1,2,1)$ & $\begin{array}{c}0,31 \\
{[0,73]}\end{array}$ \\
\hline Modelo 3 & $(1,0,2,0,1,2,1)$ & $\begin{array}{c}0,24 \\
{[0,79]}\end{array}$ \\
\hline Modelo 4 & $(3,1,4,0,1)$ & $\begin{array}{c}0,55 \\
{[0,55]}\end{array}$ \\
\hline Modelo 5 & $(1,0,4,0,1,2,1)$ & $\begin{array}{c}0,69 \\
{[0,94]}\end{array}$ \\
\hline Modelo 6 & $(1,0,2,0,1,2,1)$ & $\begin{array}{c}0,17 \\
{[0,83]}\end{array}$ \\
\hline
\end{tabular}

Teste LM Breusch - Godfrey: $H_{0}=$ Ausência de Autocorrelação Serial

Definidas as defasagens do modelo e confirmada a ausência de autocorrelação, o passo seguinte é a verificação da existência de vetores de cointegração entre as variáveis de cada modelo. A Tabela 3 apresenta os resultados dos testes de cointegração (Bounds Testing Approach) de cada estimação. A hipótese nula de ausência de vetores de cointegração entre as variáveis é rejeitada no nível de $10 \%$ e $5 \%$ de significância estatística em todos os modelos, dado que os valores da estatística $\mathrm{F}$ excedem as respectivas bandas superiores de valores críticos calculados por Pesaran et al. (2001). Isto significa que se confirma a existência dos vetores de cointegração nos seis modelos estimados, ou seja, as variáveis elencadas têm relações entre si no longo prazo. Desse modo, os resultados corroboram que as transações correntes, o saldo de investimento direto de recursos no país, a poupança interna, bem como a taxa de câmbio, de juros e a inflação, em conjunto, se inter-relacionam com o produto da economia no longo prazo.

Procedendo com a análise empírica, após a verificação da existência de cointegração entre as variáveis dos modelos, pode-se estimar os coeficientes dessa relação de longo prazo, aqui apresentados na Tabela 4. A primeira coluna da Tabela 4 mostra que, no modelo 1 , os coeficientes estatisticamente significantes são referentes à taxa de câmbio (a 10\% de significância) e à taxa de juros Selic (a 5\% de significância), sendo esta com sinal negativo. A variável relevante do modelo 1 , poupança externa (se), não apresenta significância estatística, sugerindo que poupança externa por si só, neste modelo 1, não se relaciona com o PIB no longo prazo. 
Tabela 3: Teste de Cointegração - Poupança Externa e PIB

\begin{tabular}{|c|c|c|c|c|c|c|}
\hline \multirow{3}{*}{ Modelo } & \multirow{3}{*}{ Estatística F } & \multicolumn{4}{|c|}{ Valores Críticos } & \multirow{3}{*}{$\begin{array}{c}\text { Cointegração } \\
\text { de Longo Prazo }\end{array}$} \\
\hline & & \multicolumn{2}{|c|}{ Limite $I(0)^{1}$} & \multicolumn{2}{|c|}{ Limite I(1) ${ }^{1}$} & \\
\hline & & $10 \%$ & $5 \%$ & $10 \%$ & $5 \%$ & \\
\hline Modelo 1 & 6,82 & 2,45 & 2,86 & 3,52 & 4,01 & Sim \\
\hline Modelo 2 & 5,20 & 2,12 & 2,45 & 3,23 & 3,61 & Sim \\
\hline Modelo 3 & 5,13 & 2,12 & 2,45 & 3,23 & 3,61 & Sim \\
\hline Modelo 4 & 6,48 & 2,45 & 2,86 & 3,52 & 4,01 & Sim \\
\hline Modelo 5 & 4,32 & 2,12 & 2,45 & 3,23 & 3,61 & Sim \\
\hline Modelo 6 & 5,09 & 2,12 & 2,45 & 3,23 & 3,61 & Sim \\
\hline
\end{tabular}

1 Pesaran et al. (2001) - com constante e tendência

$H_{0}=$ Ausência de Vetores de Cointegração

Já para o modelo 2 os coeficientes são significantes para todas as variáveis macroeconômicas de ajuste do modelo, a saber: taxa de câmbio, inflação IPCA, taxa de juros Selic e a proxy do investimento FBCF, o que indica que estas variáveis afetam o PIB no longo prazo. Ambas as poupanças, interna e externa (se e si), não apresentaram significância estatística no longo prazo. Ademais, o modelo 3 apresenta resultados semelhantes ao do modelo 2 , o que era esperado dada à similaridade de ambos, com impactos estatísticos das variáveis de controle e ausência de relações estatísticas significantes para a poupança externa e a poupança interna, com o "efeito Dilma" diluído.

A Tabela 4 também mostra as variáveis estatisticamente significantes que afetam o investimento direto no país (modelos 4,5 e 6), em substituição à poupança externa do trio de modelos que os antecedeu (1, 2 e 3$)$. A série de investimento direto no país $(i d p)$, relativa à poupança externa aplicada no Brasil, não se mostrou estatisticamente significante no longo prazo em nenhum dos modelos.

Os resultados apresentados na Tabela 4 pertinentes à nulidade de significância estatística nos coeficientes de longo prazo das principais variáveis da pesquisa, que são as transações correntes ( $s e$ e os investimentos no país $(i d p)$, revelam indícios que corroboram as argumentações apresentadas pela visão crítica ante a política de crescimento com poupança externa. Como já mencionado, estes argumentos se baseiam na inexpressiva elevação do investimento interno no longo prazo, dados os efeitos apreciativos sobre a taxa de câmbio, além do distanciamento da estabilidade macroeconômica, com a possibilidade de crise de demanda interna e da dívida externa. Dessa forma, os resultados da Tabela 4 se distanciam dos preceitos da visão convencional, de que a política de déficits recorrentes nas transações 
Tabela 4: Coeficientes de Longo Prazo

\begin{tabular}{|c|c|c|c|c|c|c|}
\hline & $\begin{array}{l}\text { Modelo } 1 \\
(3,0,4,3,1)\end{array}$ & $\begin{array}{c}\text { Modelo } 2 \\
(1,0,2,0,1,2,1)\end{array}$ & $\begin{array}{c}\text { Modelo } 3 \\
(1,0,2,0,1,2,1)\end{array}$ & $\begin{array}{l}\text { Modelo } 4 \\
(3,1,4,0,1)\end{array}$ & $\begin{array}{c}\text { Modelo } 5 \\
(1,0,4,0,1,2,1)\end{array}$ & $\begin{array}{c}\text { Modelo } 6 \\
(1,0,2,0,1,2,1)\end{array}$ \\
\hline Variáveis & $\begin{array}{c}\text { Coeficiente } \\
\text { [prob] }\end{array}$ & $\begin{array}{c}\text { Coeficiente } \\
\text { [prob] }\end{array}$ & $\begin{array}{c}\text { Coeficiente } \\
\text { [prob] }\end{array}$ & $\begin{array}{c}\text { Coeficiente } \\
\text { [prob] }\end{array}$ & $\begin{array}{c}\text { Coeficiente } \\
\text { [prob] }\end{array}$ & $\begin{array}{c}\text { Coeficiente } \\
\text { [prob] }\end{array}$ \\
\hline$s e_{t}$ & $\begin{array}{c}-0,10 \cdot 10^{-1} \\
{[0,14]}\end{array}$ & $\begin{array}{c}-0,12 \cdot 10^{-3} \\
{[0,14]}\end{array}$ & $\begin{array}{c}0,29 \cdot 10^{-3} \\
{[0,11]}\end{array}$ & - & - & - \\
\hline$s i_{t}$ & - & $\begin{array}{c}-0,35.10^{-3} \\
{[0,69]}\end{array}$ & - & - & $\begin{array}{c}0,30 \cdot 10^{-2} \\
{[0,72]}\end{array}$ & - \\
\hline$s i D_{t}$ & - & - & $\begin{array}{c}-0,25.10^{-3} \\
{[0,48]}\end{array}$ & - & - & $\begin{array}{c}-0,58.10^{-5} \\
{[0,97]}\end{array}$ \\
\hline$i d p_{t}$ & - & - & - & $\begin{array}{l}-0,63 . \\
{[0,36]}\end{array}$ & $\begin{array}{r}0,21 . \\
{[0,16]}\end{array}$ & $\begin{array}{r}0,33 \\
{[0,16]}\end{array}$ \\
\hline$e_{t}$ & $\begin{array}{l}0,2512 \\
{[0,08]}\end{array}$ & $\begin{array}{l}0,0601 \\
{[0,00]}\end{array}$ & $\begin{array}{l}0,0628 \\
{[0,00]}\end{array}$ & $\begin{array}{l}0,0814 \\
{[0,71]}\end{array}$ & $\begin{array}{l}0,0358 \\
{[0,09]}\end{array}$ & $\begin{array}{l}0,0597 \\
{[0,00]}\end{array}$ \\
\hline$\pi_{t}$ & $\begin{array}{r}-0,0514 \\
{[0,81]}\end{array}$ & $\begin{array}{l}0,1906 \\
{[0,00]}\end{array}$ & $\begin{array}{l}0,1887 \\
{[0,00]}\end{array}$ & $\begin{array}{r}-0,0225 \\
{[0,92]}\end{array}$ & $\begin{array}{l}0,2014 \\
{[0,00]}\end{array}$ & $\begin{array}{r}-0,2011 \\
{[0,00]}\end{array}$ \\
\hline$r_{t}$ & $\begin{array}{c}-0,03358 \\
{[0,04]}\end{array}$ & $\begin{array}{c}-0,02145 \\
{[0,01]}\end{array}$ & $\begin{array}{c}-0,14 \cdot 10^{-3} \\
{[0,01]}\end{array}$ & $\begin{array}{r}-0,30.10^{-1} \\
{[0,13]}\end{array}$ & $\begin{array}{c}-0,47.10^{-3} \\
{[0,00]}\end{array}$ & $\begin{array}{c}-0,26 \cdot 10^{-3} \\
{[0,00]}\end{array}$ \\
\hline$I_{t}$ & - & $\begin{array}{c}0,34208 \\
{[0,00]}\end{array}$ & $\begin{array}{c}0,35014 \\
{[0,00]}\end{array}$ & - & $\begin{array}{c}0,31025 \\
{[0,00]}\end{array}$ & $\begin{array}{c}0,30251 \\
{[0,00]}\end{array}$ \\
\hline constante & $\begin{array}{l}4,8114 \\
{[0,02]}\end{array}$ & $\begin{array}{l}1,4995 \\
{[0,00]}\end{array}$ & $\begin{array}{l}1,5414 \\
{[0,00]}\end{array}$ & $\begin{array}{l}5,4825 \\
{[0,08]}\end{array}$ & $\begin{array}{l}1,6401 \\
{[0,00]}\end{array}$ & $\begin{array}{l}1,6327 \\
{[0,00]}\end{array}$ \\
\hline
\end{tabular}

correntes, como meio de auferir poupança externa, levaria à melhoria na eficiência da alocação de recursos, estimulando o crescimento econômico de longo prazo. Desse modo, apesar de todas as estimações feitas mostrarem certa relação de longo prazo, quando se coloca uma lupa em cada variável específica pode-se perceber que aquelas relativas à poupança externa não parecem ser as mais relevantes para o crescimento econômico de longo prazo no Brasil.

A relação de longo prazo detectada nas estimações, com pouca relevância dada para a poupança externa, não isenta os modelos estimados de serem acometidos por choques de curto prazo. No entanto, para que a relação de cointegração seja sempre mantida, há que se ter um mecanismo de correção destes choques para se retornar à dinâmica de longo prazo. Esta é justamente a função do Mecanismo de Correção de Erros. Assim, são estimados os seis modelos na forma de vetores de correção de erros (ARDL- ECM) para a obtenção dos coeficientes de ajustamento de curto prazo. A Tabela 5 apresenta tais resultados e mostra que os 
coeficientes de correção de erros (ECM) estimados se apresentaram estatisticamente significantes a $1 \%$, como indica o p-valor entre colchetes na quarta coluna.

No modelo 1, segundo a Tabela 5, o coeficiente da equação de correção de erros (ECM) de -0,08 é estatisticamente significante, sugerindo que $8 \%$ do desvio da trajetória de longo prazo do sistema estimado são corrigidos pelos seus ajustamentos de curto prazo no trimestre seguinte. Este é o menor deles, visto que os modelos 2 e 3 apresentam coeficientes de 0,51 e 0,50 , o que implica que $50 \%$ e $51 \%$, respectivamente, do desvio da trajetória de longo prazo dos sistemas estimados são corrigidos pelos seus ajustamentos de curto prazo no trimestre seguinte. Ademais, estes mesmos desvios representam $38 \%$, 46\% e 51\% nos modelos 4,5 e 6 , respectivamente, conforme indica a coluna 3 da Tabela 5. Isso quer dizer que, na média, $40 \%$ de um possível choque de curto prazo se dissipa em um trimestre. Supondo uma relação linear, $80 \%$ de um choque se dissipa em 2 trimestres, o que vem a ser muito rápido.

Tabela 5: Mecanismo de Correção dos Erros

\begin{tabular}{c|c|c|c}
\hline Modelo ARDL & Defasagens & ECM(-1) & {$[$ Prob] } \\
\hline Modelo 1 & $(3,0,4,3,1)$ & $-0,08$ & {$[0,00]$} \\
Modelo 2 & $(1,0,2,0,1,2,1)$ & $-0,51$ & {$[0,00]$} \\
Modelo 3 & $(1,0,2,0,1,2,1)$ & $-0,50$ & {$[0,00]$} \\
Modelo 4 & $(3,1,4,0,1)$ & $-0,38$ & {$[0,00]$} \\
Modelo 5 & $(1,0,4,0,1,2,1)$ & $-0,46$ & {$[0,00]$} \\
Modelo 6 & $(1,0,2,0,1,2,1)$ & $-0,51$ & {$[0,00]$} \\
\hline
\end{tabular}

Estes resultados da Tabela 5 são bastante interessantes, principalmente quando aplicados à dinâmica da política de crescimento com poupança externa, tema central deste trabalho. Como já vimos, apesar de haver relação de longo prazo entre as variáveis estimadas em todos os modelos, a influência específica da poupança externa para o crescimento de longo prazo não revela significância estatística alguma. Todavia, não exime a possibilidade e, inclusive, comprova a existência de choques de curto prazo, conforme atentam os mecanismos de correção de erros. Além disso, os resultados estatisticamente significantes destes choques podem revelar mais um ponto de consonância com a visão crítica, que apregoa um possível impacto da poupança externa sobre o crescimento no curto prazo, quando limites ao endividamento não são atingidos.

Para ver isso, devemos analisar quais variáveis são estatisticamente significantes no curto prazo. A Tabela 6 traz estes valores. A segunda coluna apresenta apenas as variáveis significativas a $5 \%$ de cada modelo. Por exemplo, no modelo 1 , o PIB defasado em dois períodos, a poupança externa e a taxa de câmbio real, e defasada em três períodos são significantes.

A terceira coluna da Tabela 6 destaca o comportamento dos coeficientes de curto prazo das transações correntes, ou poupança externa (se) e do investimento 
direto no país (idp), ambas fundamentais na sustentabilidade de cada modelo. É importante ressaltar que apenas no modelo 1 a 'se' é relevante a $1 \%$ estatisticamente. Nos outros modelos, nem 'se' e nem 'ipd' se mostram significantes estatisticamente no curto prazo. Destaque aqui para o sinal nos coeficientes, que revela uma relação negativa sobre o PIB e não positiva, conforme defendido na teoria. Em resumo, nem mesmo um impacto relevante da poupança externa sobre o crescimento no curto prazo parece ter sustentabilidade no caso brasileiro.

Os resultados das tabelas desta seção compilados revelam: i) ausência de autocorrelação; ii) confirmação da cointegração de longo prazo entre as variáveis, mas com pouca relevância das poupanças externa e interna; iv) apenas poupança interna relevante no curto prazo em um dos seis modelos estimados, o que é condizente com o que era esperado a priori pela visão crítica de que a 'se' poderia sim repercutir sobre o PIB, no curto prazo, ainda que de forma inexpressiva. Tais ocorrências empíricas indicam consonância com as premissas teóricas da visão crítica.

Tabela 6: Coeficientes de Curto Prazo

\begin{tabular}{|c|c|c|}
\hline $\begin{array}{l}\text { Modelo } \\
\text { ARDL }\end{array}$ & Variáveis Significantes a 5\% & $\begin{array}{c}\text { Comportamento da poupança externa } \\
\text { Coeficiente [prob] }\end{array}$ \\
\hline Modelo 1 & $y_{t-2} ; s e_{t} ; e_{t} ; e_{t-3}$ & \begin{tabular}{cc}
\multicolumn{3}{c}{ Se } \\
$-0,00014 \quad[0,01]$
\end{tabular} \\
\hline Modelo 2 & $e_{t} ; \pi_{t} ; I_{t} ; I_{t-1}$ & $\begin{array}{c}\text { Se } \\
-0,25147 \quad[0,12]\end{array}$ \\
\hline Modelo 3 & $y_{t-1} ; e_{t} ; \pi_{t} ; e_{t-1} ; I_{t-1} ; I_{t-2}$ & $\begin{array}{cc}\text { Se } \\
-0,03643 \quad[0,54]\end{array}$ \\
\hline Modelo 4 & $y_{-1} ; y_{-2} ; y_{-3} ; e_{t} ; e_{t-1}$ & $\begin{array}{c}i d p \\
-0,09128 \quad[0,80]\end{array}$ \\
\hline Modelo 5 & $y_{t-1} ; e_{t} ; \pi_{t} ; e_{t-1} ; I_{t} ; I_{t-1} ; I_{t-2}$ & $\begin{array}{c}\text { idp } \\
-0,00142 \quad[0,16]\end{array}$ \\
\hline Modelo 6 & $e_{t} ; \pi_{t} ; I_{t} ; I_{t-1}$ & $\begin{array}{c}d p \\
0,00025 \quad[0,14]\end{array}$ \\
\hline
\end{tabular}

\section{Testes de Estabilidade dos Coeficientes da Regressão}

Os testes descritos por Brown, Durbin e Evans (1975) são os de Soma Cumulativa dos Resíduos Recursivos (CUSUM) e Soma Cumulativa dos Quadrados dos Resíduos Recursivos (CUSUMQ), ambos adequados para testar a estabilidade dos coeficientes das regressões,foram realizados para os seis modelos estimados. Estes dois testes são reportados em forma gráfica e estão explicitados aos pares por modelo no anexo.

As linhas pontilhadas apresentam a banda de valores críticos, calculados a $5 \%$ de significância estatística, cuja a hipótese nula é de estabilidade dos coeficientes. Dessa forma, o ideal para não se rejeitar a hipótese nula e, portanto, atestar a estabilidade dos parâmetros estimados, é que a linha contínua fique dentro dos limites das bandas pontilhadas. Cabe destacar que os processos CUSUM e CUSUMQ representam testes importantes como forma de identificar a existências de quebras 
estruturais do modelo econométrico. A ideia principal de examinar o comportamento dos resíduos é extrair evidências de alterações de estrutura. Dessa forma, as estimativas recursivas dos parâmetros observam o desempenho preditivo do modelo e são testes formais com hipóteses claramente definidas com os quais pretende-se verificar a existência de erros de especificação, por exemplo.

Os gráficos de todos os modelos mostram que os valores críticos de CUSUM e CUSUMQ estão dentro da banda de valores críticos, calculados a $5 \%$ de significância estatística. O teste CUSUM do modelo 4 revela que o limite superior mostra leve extrapolação no final do período. Esta pequena instabilidade é corrigida quando se aumenta o número de defasagens deste modelo, de 4 para 5 defasagens. Assim, a hipótese nula de estabilidade dos coeficientes não é rejeitada para nenhum dos testes realizados. Isso indica que não há evidências de alterações de estrutura dos parâmetros dos modelos estimados.

\section{CONSIDERAÇÕES FINAIS}

O déficit na conta-corrente é fomentado estrategicamente como meio de política de crescimento econômico do país visando à utilização da poupança externa com via de estímulo ao investimento e, por conseguinte, geração de crescimento econômico. Esta política é apoiada pela teoria econômica convencional, todavia não é amplamente aceita. As premissas críticas baseiam-se fundamentalmente na inexpressiva elevação do investimento interno, dado que os efeitos apreciativos sobre a taxa de câmbio e a propensão a consumir dos agentes poderiam ocasionar crise fiscal. Ademais, esta política seria improdutiva dados os limites ao endividamento e distanciamento da estabilidade macroeconômica, com a possibilidade de crise de demanda interna e da dívida externa, além de desequilíbrios na balança comercial.

A partir deste contexto, o que se investigou empiricamente neste ensaio é se a política de crescimento com poupança externa consegue suprir o déficit na poupança interna brasileira e elevar o seu nível de atividade e enquadrar a realidade brasileira a uma das visões dispostas na literatura. Para atingir tal objetivo, foram utilizados Modelos Autorregressivos de Defasagens Distribuídas (ARDL) aliados à cointegração, para dados trimestrais, a partir do último trimestre de 1999 até o final de 2017. Este método foi escolhido pela possibilidade de testar a existência de cointegração entre as variáveis do modelo e, principalmente, por apresentar uma dinâmica de curto e longo prazo de cada sistema estimado, dando a possibilidade de testar empiricamente as duas óticas teóricas vigentes.

As variáveis utilizadas para os testes empíricos baseiam-se prioritariamente no déficit da poupança interna brasileira (si), no influxo de recursos externos, considerando a poupança externa do Brasil (déficits em transações correntes) e a poupança externa aplicada no Brasil (idp - investimentos diretos no País) e, por fim no PIB brasileiro. Ademais, como variáveis de controle dos modelos empíricos, em consonância com a literatura econômica, utilizamos a taxa de juros Selic; inflação IPCA; FBCF como proxy do investimento, e a taxa de câmbio.

Dos resultados empíricos de seis equações estimadas, tendo todas elas como 
o produto da economia como variável dependente, destacam-se o comportamento dos coeficientes de curto prazo das transações correntes, chamada poupança externa (se), e do investimento direto no País (idp) como relevante a $1 \%$ estatisticamente, em apenas um dos modelos estimados não sendo mais 'se' e 'idp' significantes estatisticamente no curto prazo em nenhum dos demais modelos. Ênfase aqui para o sinal dos coeficientes, que se apresentou negativo em todas as estimações indicando uma relação oposta de determinação sobre o PIB e não positiva conforme defendem os teóricos clássicos.

Ademais, a nulidade de significância estatística nos coeficientes de longo prazo das transações correntes (se) e dos investimentos diretos no país (idp), revelam indícios que corroboram os argumentos apresentados pela visão crítica ante a política de crescimento com poupança externa. A centralidade argumentativa da visão crítica se baseia na ausência de estímulos ao investimento interno no longo prazo, dado que os efeitos apreciativos sobre a taxa de câmbio, tendem a elevar o consumo internamente e não estimulam o incremento de capacidade produtiva gerando distanciamento da estabilidade macroeconômica, com a possibilidade de crise de demanda interna e de balança de pagamentos.

\section{REFERÊNCIAS BIBLIOGRÁFICAS}

ALVES, V. S. V.; SILVA, C. G.; LOPES, D. T. (2010) Déficit em Conta-corrente, Poupança Externa e Gasto Público no Brasil: uma análise empírica. Anais do XXXVIII Encontro Nacional de Economia, ANPEC.

AURÉLIO, M. M. (1997) Poupança externa e o financiamento do desenvolvimento. Texto para discussão, n. 496. Coordenação Geral de Finanças Públicas e Política Fiscal do IPEA.

BRESSER-PEREIRA, L. C. (2010) Déficit, poupança e crescimento. Economia \& Tecnologia, v. 6, n.3, p. 22-45, jul-set.

BRESSER-PEREIRA, L. C. e NAKANO; Y. (2003) Crescimento Econômico como Poupança Externa? Revista de Economia Política, v. 23, n. 2 (90), p. 3-27, abr-jun.

BRESSER-PEREIRA, L. C. (2007a) Substituição de poupanças. In: BRESSER-PEREIRA, L. C. Macroeconomia da Estagnação: Crítica da ortodoxia convencional no Brasil pós-1994, Editora São Paulo, cap. 05, p. 149-166.

BRESSER-PEREIRA, L. C.; GALA, P. (2007b) Por que a poupança externa não promove crescimento? Revista de Economia Política, v. 27, n. 1 (105), p. 3-19, jan-mar.

BRESSER-PEREIRA, L. C.; GONZALEZ, L.; LUCINDA, C. (2008) Crises financeiras nos anos $1990 \mathrm{e}$ poupança externa. Nova Economia, v. 18, n. 3, p. 327-357, set-dez.

DAMASCENO, A. O. (2007) Integração financeira internacional e crescimento econômico: uma crítica à abordagem convencional. Economia e Sociedade, v. 16, n. 2 (30), p. 171-198, ago.

DICKEY, D. A.; FULLER, W. A. (1979) Distribution of the estimators for autoregressive time series with a unit root. Journal of the American Statistical Association, n. 74(366a), p. 427-431.

DORNBUSCH, R.; GOLDFAJN, I.; VALDES, R. O. (1995) Currency Crises and Collapses. Brookings Papers on Economic Activity, v. 26, n. 2, p. 219-294.

EDWARDS, S. (1995) Why are savings rates so different across countries? An international comparative analysis. NBER Working Paper; n. 5097; Cambridge, MA.

EINCHENGREEN, B.; LEBLANG, D. (2003) Capital account liberalization and growth: was Mr. Mahathir right? International Journal of Finance and Economics, v. 8, n. 3, p. 205-224, sept.

ELLIOT, G.; ROTHEMBERG, T.; STOCK, J. H. (1996) Efficient tests for an autoregressive unit root. Econometrica, v. 64, n. 4, p. 813-836. 
ENGLE, R. F. GRANGER, C. W. J. (1987) Co-integration and error correction: representation, estimation and testing. Econometrica, n. 55, p. 251-76.

FELDSTEIN, M.; HORIOKA, C. (1980) Domestic saving and international capital flows. The Economic Journal, v. 90, n. 358, p. 314-329, jun.

JOHANSEN, S. (1991) Estimation and hypothesis testing of cointegration vectors in Gaussian vector autoregressive models. Econometrica, n. 59, p. 1551-1580.

KWIATKOWSKI, D.; PHILLIPS, P. C. B.; SCHMIDT, P.; SHIN, Y. (1992) Testing the null hypothesis of stationary against the alternative of a unit root: how sure are we that economic time series are non-stationary? Journal of Econometrics, n. 54, n. 1-3, p. 159-178.

OBSTFELD, M.; ROGOFF, K. (2000) The six major puzzles in international macroeconomics: Is there a common cause? In: Bernanke, B. \& Rogoff, K. NBER Macroeconomics Annual 2000, 15, p. 339-390.

PESARAN, M. H., SHIN, Y., SMITH, R. P. (1999) Pooled Mean Group Estimation of Dynamic Heterogeneous Panels. Journal of the American Statistical Association, v. 94 (446), p. 621-634.

PESARAN, M. H.; SHIN, Y. (1999) An Autoregressive Distributed-Lag Modelling Approach to Cointegration Analysis. Econometrics and Economic Theory in the 20th Century: The Ragnar Frisch Centennial Symposium. Cambridge University Press.

PESARAN, M. H.; SHIN, Y.; SMITH, R. J. (2001) Bounds testing approaches to the analysis of level relationships. Journal of Applied Econometrics, v. 163, p. 289-326.

PHILLIPS, P. C. B. e HANSEN, B. E. (1999) Statistical inference in instrumental variables regression with i (1) processes. The Review of Economic Studies, v. 57 (1), p. 99-125.

PHILLIPS, P. C. B.; PERRON, P. (1988) Testing for a unit root in time series regression. Biometrika, v. 75, n.2, p. 335-346.

ROCHA, M. A. A.; OREIRO, J. L. (2011) Acumulação de capital, poupança externa e desempenho macroeconômico dos países emergentes. Economia e Sociedade, v. 20, n.1, p.33-52, abril.

SCHIMDT HEBBEL, K.; WEBB, S. e CORSETTI, G. (1992) Household saving in developing countries: first cross-country evidence. The World Bank Economic Review, v.6, n.3, p. 529-547.

UTHOFF, A.; TITELMAN, D. (1998) The relationship between foreign and national savings under financial liberalization. In: Capital Flows and Investment Performance, Lessons from Latin America. Paris: OECD Publishing, cap.2, p.23-42.

\section{ANEXO - TESTES DE ESTABILIDADE}

\section{DOS COEFICIENTES (CUSUM) E (CUSUMQ)}

Modelo 1
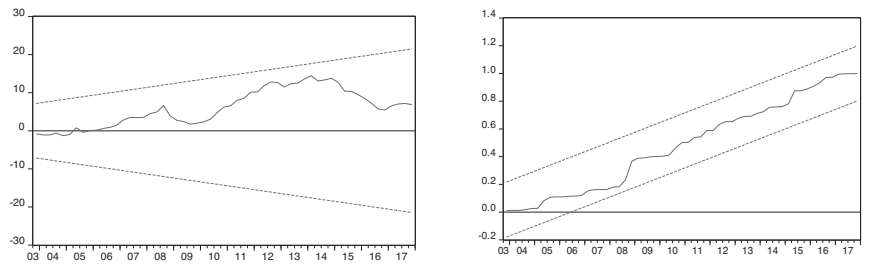

_ Cusum -----. $5 \%$ Significance

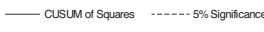

Modelo 2
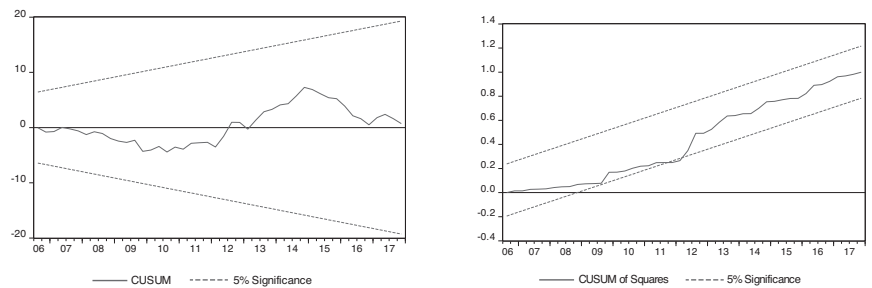
Modelo 3
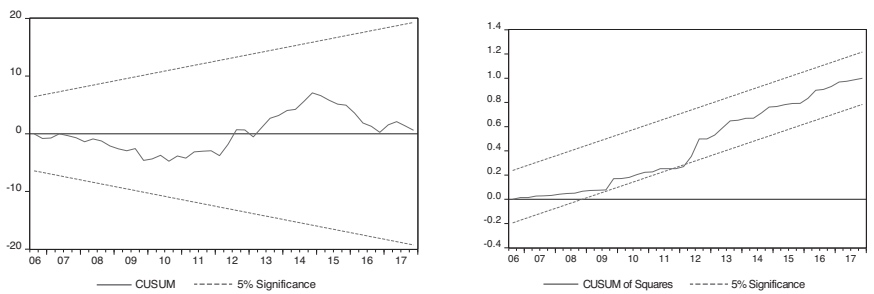

Modelo 4
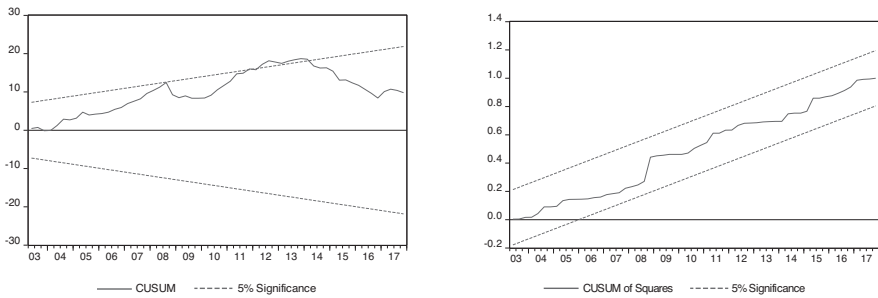

__ CUSUM --.--- 5\% Significance

__ CUSUM of Squares ------ $5 \%$ Significano

Modelo 5
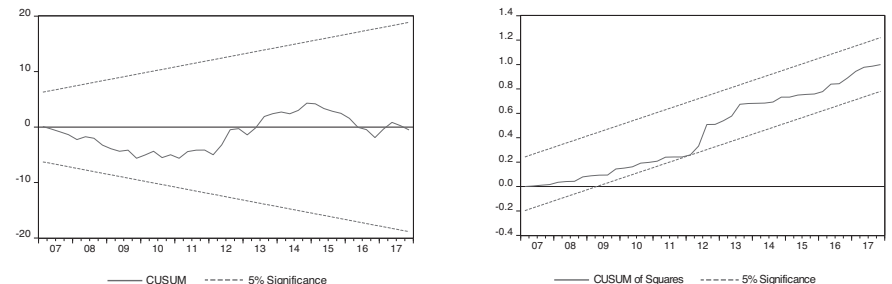

Modelo 6
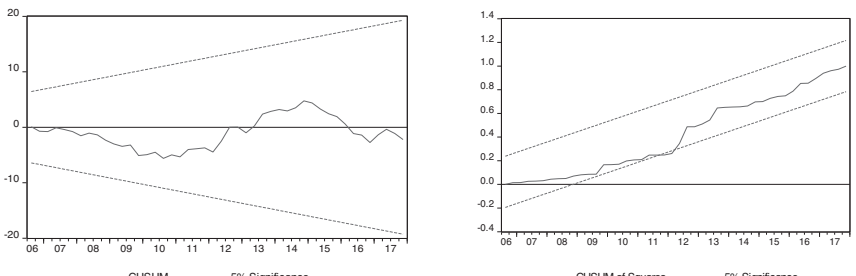

_ CUSUM of Squares .-.--.. 5\% Significance 